\title{
Comment on: Tools Measuring Quality of Death, Dying, and Care, Completed After Death: Systematic Review of Psychometric Properties
}

\author{
José E. Montoya-Medina ${ }^{1,2} \cdot$ Giordana Poletti-Jabbour $^{1} \cdot$ Nicole Urrunaga $^{1} \cdot$ Heyson A. Jiménez ${ }^{1}$
}

Published online: 3 December 2018

C) Springer Nature Switzerland AG 2018

\section{Dear Editor,}

The perception of good death has not been studied in Latin-American countries despite the importance of understanding what health professionals and patients (and their relatives) think about this subject. We have read with interest the article entitled "Tools measuring Quality of Death, Dying, and Care, Completed after Death: Systematic Review of Psychometric Properties" [1] reporting the validity and applicability of several questionnaires measuring good death, including the short version of the Good Death Inventory (GDI), developed and validated in the Japanese population [2].

In that context, a study was conducted to measure the perception of good death in Peru using the short version of the GDI, as used by Meffert et al. in Germany [3]. For this, the short version of the GDI went through a process of translation, reverse translation and cultural adaptation from English to Spanish by an expert committee. Medical students from a private university in Lima, Peru, were surveyed during 2016 utilizing this adapted version. A total of 296 students were enrolled. The mean age of the sample was 20.7 (standard deviation 2.3) years. One hundred and twenty-nine (43.6\%) were females, and students were from different years of their career. Using the criteria in the aforementioned publication, we determined that the GDI had a Cronbach's alpha of 0.90 and a kappa test of 0.35 in the

An author's reply to this comment is available at: https://doi. org/10.1007/s40271-018-0351-3.

This comment refers to the article available at: https://doi org/10.1007/s40271-018-0328-2.

José E. Montoya-Medina

jmontoyam96@gmail.com

1 Peruvian University of Applied Sciences, Lima, Peru

2 Sociedad Científica de Estudiantes de Medicina UPC (SOCIEMUPC), Lima, Peru study population. A confirmatory factorial analysis was also conducted, concluding that only one factor explained $56.4 \%$ of the tool's variance.

In conclusion, despite getting a negative score for the kappa test, the short version of the GDI was useful for measuring the perception of good death in medical students, as this tool is relatively short (i.e., only has 18 items) and was culturally adapted to our population. We hope this information will contribute to support the use of this tool.

\section{Compliance with Ethical Standards}

Conflict of interest The authors, José E. Montoya-Medina, Giordana Poletti-Jabbour, Nicole Urrunaga, and Heyson A. Jiménez, declare there is no conflict of interest.

\section{References}

1. Kupeli N, Candy B, Tamura-Rose G, et al. Tools measuring quality of death, dying, and care, completed after death: systematic review of psychometric properties. Patient. 2018. https://doi. org/10.1007/s40271-018-0328-2.

2. Miyashita M, Morita T, Sato K, Hirai K, Shima Y, Uchitomi Y. Good death inventory: a measure for evaluating good death from the bereaved family member's perspective. J Pain Symptom Manag. 2008;31(35):486-98.

3. Meffert C, Stößel U, Körner M, Becker G. Perceptions of a good death among German medical students. Death Stud. 2015;39(15):307-15. https://doi.org/10.1080/07481187.2014.951496 (epub 2015 Apr 7). 